\title{
The Analysis of Stochastic Processes in Unloadingthe Energywillow Cuttings from the Hopper
}

\author{
Serhii Yermakov \\ Educational and scientific laboratory \\ "DAK GPS"State Agrarian and \\ Engineering University in Podilia \\ Kamianets-Podilskyi, Ukraine \\ dakgps@pdatu.edu.ua \\ Krzysztof Dziedzic \\ Department of Mechanical Engineering \\ and Agrophisics \\ University of Agriculture in Krakow \\ Krakow, Poland \\ krzysztof.mudryk@ukr.edyu.pl
}

\author{
Hutsol Taras \\ Vice Rector for Educational, Scientific \\ and Pedagogical Affairs \\ State Agrarian and Engineering \\ University in Podilia \\ Kamianets-Podilskyi, Ukraine \\ pro-gp@pdatu.edu.ua \\ Liudmyla Mykhailova \\ Department of Electrical Machinery \\ and Electrical Equipment Operating in \\ Agriculture \\ State Agrarian and Engineering \\ University in Podilia \\ Kamianets-Podilskyi, Ukraine \\ mihajlovaimesg@gmail.com
}

\author{
Krzysztof Mudryk \\ Department of Mechanical Engineering \\ and Agrophisics \\ University of Agriculture in Krakow \\ Krakow, Poland \\ krzysztof.mudryk@ukr.edyu.pl
}

\begin{abstract}
The paper deals with the theoretical and experimental investigation of the main characteristics of woody crop cuttings unloading from the hopper. To create a variety of automated systems for material feed there is a need to ensure high performance selecting and unloading the material, in particular, it is of vital importance in designing machines for energy willow planting. The analysis of existing theories in mechanics of loose materials motion made it possible to identify the features of unloading the cuttings that narrowed the area of discussion. We will consider two half-planes located at angles to the horizontal plane as a model for hopper in pilot testing.

It is analytically and experimentally determined that woody crops cuttings flow occurs according to dry friction laws and inverse-square law and the flow is normal in nature. The statically stable formation and dynamic arches that prevent the uniform and continuous unloading are in evidence.
\end{abstract}

For the theoretical validation of results, we present a set of cuttings as the pseudo liquid that consists of two phases: a discrete phase formed by cuttings and the continuous phase (gaseous medium, air). Each of these phases in terms of the mechanics of multiphase systems is represented as a solid medium with certain characteristics. According to these assumptions, the process unloading of such structure from the hopper can be modelled on the basis of methods of hydrodynamics of multiphase systems. In such a case the field speeds of such pseudo liquid must satisfy the NavierStokes equation type.

The analytical and empirical analysis of unloading the energy willow cuttings helps to prove theoretically the possibility of enhancing the process of planting till its full automation. As a result, the study gives the theoretical formula that evaluates the velocity of energy willow cuttings flow, the adequacy of which is partially tested in pilot experiments conducted by the authors of the paper in the process of creating the planting machine.

Using the received data for further research will make it possible to take into account all the factors involved in unloading and bridging, which is important for examining and improving this process.

Keywords - wood cuttings, bridging, hopper, automatic planting, pseudo liquid.

\section{INTRODUCTION}

The production of alternative renewable energy sources is a priority direction in the development of the nation's economy, and the use of bio-feedstock, including energy crops, as fuel, is one of the strategic path ways. Therefore, it is important to ensure high-performance of machines for plantings of such crops. It is well-known that machines for energy willow or poplar planting use, primarily, hand supply of planting material that significantly limits both quantitative and qualitative characteristics of this device. Therefore, the development of the planting machine for such crops is a significant engineering challenge.

Willow and Poplar are cloned for energy purposes by planting cuttings with the diameter of $15-20 \mathrm{~mm}$ and the length of $20-30 \mathrm{~cm}$. The features of such material determine the main complexity in its loading. If the studies on the mechanics of small lump granular materials movement are frequent $[2,3,4,5,6]$, the research on this kind of materials lack.

The necessary part of machines and units (both mobile and stationary) that are designed for the bulk materials are tankers of different shapes and sizes. Obviously, to develop the automated system of cuttings flow we should consider the issue hopper. Therefore, the aim of this research is the study of stochastic processes in pouring

Online ISSN 2256-070X

http://dx.doi.org/10.17770/etr2019vol3.4159

(C) 2019 Serhii Yermakov, Hutsol Taras, Krzysztof Mudryk, Krzysztof Dziedzic, Liudmyla Mykhailova. Published by Rezekne Academy of Technologies.

This is an open access article under the Creative Commons Attribution 4.0 International License. 
the woody crops cuttings out that will provide continuous and uniform flow, transportation, navigation and setting in place ofplanting.

Materials and methods

The material for study is the rod-like body (the cuttings of woody crops). The lack of roots and relative identity of cuttings according to form size, allow us to find the solutions in the existing theories of granular material flow and to determine the peculiarities that can be applied to hardened cuttings. Moreover, such phenomena as adhesion and strength of clutches between cuttings will not influence the movement. That is why when we unload such material it will act as a free-flowing and bulk material that is characterized by dry friction determined by inverse-square law. Taking into account the mentioned information we can use the mathematical models of the discrete granular body (for example, the theory of L. Hiachev, V. Bohomiahkykh) for examining the cuttings flow from the tanker.

The models of the tanker for cuttings unloading in our experimental research will be two half-planes set at the angles $\boldsymbol{\alpha}$ and $\boldsymbol{\beta}$ to the horizontal plane (fig. 1).

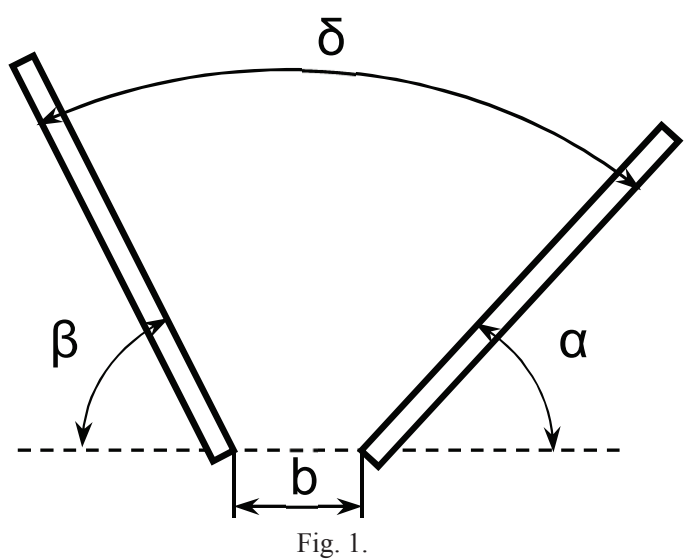

Hopper model for unloading the energy willow cuttings.

To process data, the conclusions of the various theories on free-flowing material flow and empirical studies conducted at the laboratory installation in State Agrarian and Engineering University in Podilia were used.

\section{RESUlts AND DISCUSSION}

The productivity of machines and technological lines of various industrial complexes in general and agriculture in particular, depends, primarily, on the bandwidth of the feed items - the tankers. In addition, tankers not only receipt and issue the material, they often work as transporting units, dosing devices. It, consequently, gives the reason to consider them as an important link in terms of automatic or automated functioning of machines, as well as the differential regulation of control systems.

The features of the shapes and sizes of such material as energy crops cuttings influence also the mechanics of their flowing terms of their gravity discharging from the tanker. The explanation of the process of the movement of such material can be found in the theories of granular materials flow in terms of dry friction.

As far as scientific theories are concerned, starting from the end of the 19th century scientists explore the mechanics of granular bodies that is shown in the following conclusions:

- the pressure on the bottom of reservoirs is significantly lower than the weight of the material. Besides, at some height of material layer, this pressure remains unchanged. And therefore the flow rate and speed of granular materials do not depend on the height of backfill over the exhaust opening (Roberts, Fried, Delakroa, Bernstein);

the pressure of the granular material depends on its density and the parameters of cross-sectional mortice of unloading hole (Jansen, Zenkov);

- The bulk material can be regarded as a discrete environment (Dzhenkìn);

- thespeed and the consumption of leakage under normal flow are larger than hydraulic, due to different frequency formation of arches (Keneman);

- The phenomenon of "dynamic bridging" takes place in the process of granular materials flow (Protodiakonov, Pokrovskyi, Arefiev, Platonov, Banit);

Such conclusions for different types of granular materials are frequent. We presented only some of the patterns that can be applied to study the movement of woody crops cuttings.

The mechanical model of granular body motion designed by L. Hiachev, V. Bohomiahkykh are widely used today. The study of the scientists is an attempt to develop the first combined model for granular materials that combined its discrete and continuous properties. The authors took into consideration such physical and mechanical properties like the size of the particles, the angle of the installation, the coefficients of friction, etc. [5] L. Hiachev, for example, in his research accepts that the friction of particles of the material between each other and the walls of the tanker are dry, that allows to use these ideas for wood cuttings. V. Bohomiahkykh, in his turn, used the idea of bridging to identify the impact of unsustainable arches on the movement of grain flows in tankers and determined the frequency of formation and destruction of riveting [4]. The phenomenon described by the author were applied in our experimental research on cuttings flow [6].

The mentioned statements and theories give grounds to consider unloading energy crops cuttings as of the flow of incompressible bulk material, and the patterns of material movement in the gravitational discharge is accompanied by various phenomena that prevent movement (first of all arching) and have the stochastic nature.

On the basis of the accepted model of the tanker and the material and on the basis of the carried out analyses and laboratory experience, the process of discrete bulk material flow from the tankers can be described as follows.

At the moment of opening the damper of exhaust outlet of the hopper, the flow of loose material in it some short period of time will be transient (before the moment of destruction of the most remote from the exhaust outlet of a dynamic arch, generated in the process of unloading).

Under certain conditions, the dynamic arches become statically stable. This occurs when a polygon of forces acting on this arch, is closed. That is, in this case, the resultant of all forces acting on this arch is zero. If it is not 
zero, then statically stable set becomes unstable (dynamic) and, finally, collapses.

Statically stable arches stop the process of flow, but the probability of their development depends on the width of the discharge opening. We can always find a value for the width of the discharge opening, where such stops can be avoided. Adopting empirically this window width we can fix the material flow from the tanker in different periods of time after the start of unloading (opening the unloading window). Because the process of unloading from the symmetrically inclined walls follows the same principles, let's have a look at the phase of flow when the form of a tanker has one vertical wall (fig. 9)

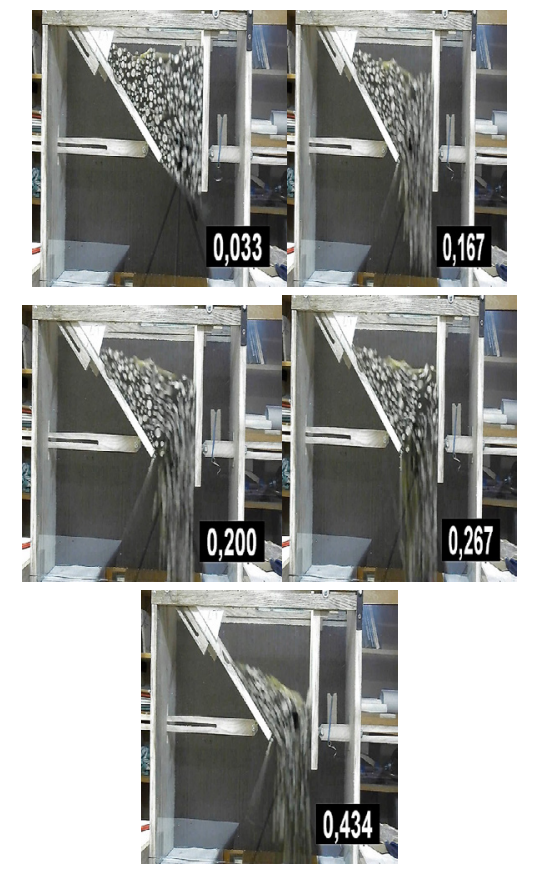

Fig. 2. Theflowphaseof energy willow cuttings from the hoppers if theslanted corners ofhalf-planesare $\alpha=90^{\circ}$ и $\beta=40^{\circ}$

Periodic stochastic arches and destruction of statically stable arches over the entire height of the moving stream in the tanker determine the periodic stochastic 3-d loosening and sealing of loose material and, therefore, causes its throbbing exit from the hopper outlet. This was confirmed by the experiments in boundary value of discharge opening width.

Consequently, the process of bridging the bulk materials that are in the boundary conditions is a natural phenomenon peculiar to loose bodies. Stochastic process of origin and fracture of arches is observed with any kind of discrete bulk material flow from the discharge opening of tankers.

This process is both discrete and continuous. Its discretion is evident in beating nature of flowing the loose material and its continuity - in laminarity (uniformity) of flow in a tanker since the moment of its inception and until its complete exit from the hopper.

Another aspect of selection the theories for studying the mechanics of unloading the granular material is a kind of material from the banker.

Taking into accountthe physical and mechanical properties of wood cuttings, as well as the form, design options, and frictional properties of walls of possible hoppers the hydraulic motion is unlikely. The normal movement of the flow, when the material over the slit window is uploaded first and then the material from the inclined walls of the hopper (fig. 3). As a result, on the surface of the material a funnel, or in our case a wedge is formed.

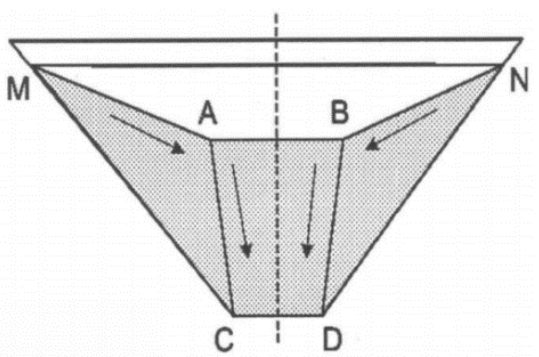

Fig. 3. The diagram of the normal motion of the material in the hopper.

The appropriate nature of cuttings flow, was confirmed by research conducted in State Agrarian and Technical University in Podilia, where the motion of energy willow cuttings in the track hopper with wooden walls $[1 ; 2]$.

The detailed analysis of cuttings movement made it possible to characterize the features of their flow. So, if you unload such material from the hopper with one vertical wall the first cuttings that are above the discharging window and along a vertical wall (fig. 2-1 and 2). On a sloping wall angled at $40^{\circ}$ the cuttings form the inactive layer. As a result of cuttings flow a wedge like hole visible from the second frame is formed in the upper layers which is clearly visible from picture 2 (fig. 2-2). In a period of time, the material falls down into the emptiness (fig. 2-4 and 5). We should mention that the material was non-mobile before (upper layers above the sloping wall). As a result, a collision between the layers is formed (fig. 2-4) that "strike" with layers of normal pouring out that have not yet had time to leave the hole. From our point of view, it is the moment when the static arch and delay of unloading (or even stop) take place. The hopper leaves the last layer of cuttings that were near the sloping wall (fig. 2-5).

It can be stated that the cuttings in the hopper move erratically: first of all, the cuttings over the unloading window move, and in the end the cuttings on the sloping wall move. Respectively, the speed of cuttings movement of the over the unloading window is always the biggest and speed of cuttings over the sloping wall is smaller and depends on the angle of its inclination. It can be concluded that the cuttings flow follows the normal rules of material flow when the pillar falls over the hole at the beginning, and then the layers from the sides start to move. Continuing the experiments different angles of installation at $\alpha$ and $\beta$ half-planes, it is possible to determine approximately the same patterns (fig. 4). 


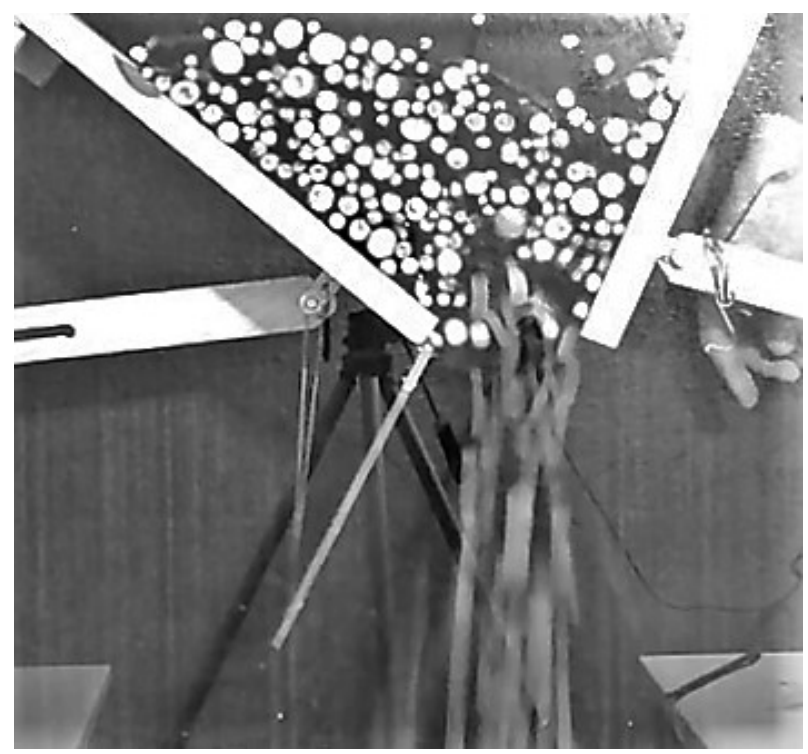

Fig. 4. The normal character of energy willow cuttings flow inSAEUP research.

For the theoretical substantiation of the specified processes, we propose to review the mechanics of cuttings motion in terms of the gravitational unloading from the point of view of dynamics of multiphase systems [10,13]. The set of cuttings is regarded as the double phase pseudo liquid, where the cuttings form the discrete phase and the second phase is the gaseous medium that fills the spaces between the cuttings. Taking into account the fact that the volume concentration of cuttings (discrete phase) is significantly larger than the similar values of continuous phase, the movement of the discrete components (aggregate cuttings) can be logically modelled as a movement of viscous incompressible pseudo liquid, velocity field of which satisfies the Navier-Stokes equation [12].

\section{CONCLUSIONS}

It follows from the above that the process of grain materials flow from the hopper is the natural process of frequent in time formation and destruction of dynamic arches over the entire height of the moving discrete stream. This process is stochastic according to both the time of formation and destruction of arched structures and the location of their formation and destruction in the volume of boundary conditions (e.g., the volume of the hopper).

The analysis of the unloading process and the form of the arches shows that such material as woody crops cuttings, besides the common causes of arches formation and patterns of their origin have some more peculiarities. One of the features of these cuttings is their rod-like form that makes the bridging difficult and invokes such additional conditions and factors as distortions of cuttings in the layer, the irregular shape of the cuttings, their uneven pinching in length, etc.

It is possible to analyze the patterns of cuttings unloading from the hopper if we create the conditions when there is no occurrence of static arches. In this case, the flow follows the principles of normal flow.

We are able to theoretically justify the results with the help of modelling the mechanics of cuttings movement based on the dynamics of multiphase systems. The material is supposed to be a two-phase incompressible pseudo liquid, the flow of which would correspond to the Navier-Stokes equation.

Using the received data in further research will make it possible to take into account all the factors involved in unloading and formation of arches that is important in examining and improving this process.

\section{REFERENCES}

[1] S.V. Yermakov, Perspektyvy udoskonalennia konstruktsii dlia sadinniazhyvtsiv enerhetychnykh kultur [Perspectives of improvement of constructions for energy crop planting]. Bulletin of State Agrarian and Engineering University in Podilya, V. 2 (26), 2017, p. 37-45. Available: http://188.190.33.56:7980/ jspui/bitstream/123456789/296/1/PB-26-29.pdf. [Accessed: Feb. 09, 2019].

[2] S.Yermakov, M.Tulej, W.Tulej, I. Shevchuk,Analiz konstruktsiy avtomativ sadinnia [Construction analysis means of plantingi automation]. Materialy XXXIV Mizhnarodnoi naukovopraktychnoi internet-konferentsii «Tendentsii ta perspektyvy rozvytku nauky i osvity v umovakh hlobalizatsii». Vypusk 34. Pereiaslav-Khmelnytskyi, 2018, p.615-619.

[3] V.A. Bohomiahkykh, A. P. Pepchuk, Intensifikaciya razgruzki bunkernyx ustrojstv v usloviyax svodoobrazovaniya zernistyx materialov [The improvement of unloading of bunker devices in terms of grain bridging]. Zernohrad, 1985, 162 p. Available: https://elibrary.ru/item.asp?id=24577674. [Accessed: Feb. 09, 2019]

[4] L.V. Gyachev, Osnovy teorii bunkerov [Fundamentals of bunker theory]. Novosibirsk: izd-vo novosibirskogo universiteta, 1992, 312 p.

[5] L.N. Tyshchenko, (2004) Intenifikaciya separirovaniya zerna [Identification of grain separation]. Kharkov: Osnova, 224 p. Available: https://elibrary.ru/item.asp?id=19507459. Access: 25th November, 2018.

[6] L. N.Tyshchenko, V. N. Olshanskyi, Vibroreshotochnaya separaciya zernovyx smesej. [Vibro latticed separation of grain mixes]. Kharkov: Misruk, 2011, 280 p.

[7] N.N. Boholiubov, J.A.Mytropolskyi, Asimptoticheskie metody $\mathrm{v}$ teorii nelinejnyx kolebanij [Asymptotic methods in the theory of nonlinear oscillations]. Moscow: Nauka, 1974, 504 p. Available: http://books.e-heritage.ru/book/10081090. Access: 25th November, 2018.

[8] M.A. Lavrentev,; B.V. Shabat, Metody teorii funkcij kompleksnogo peremennogo [Methods of the theory of functions of a complex variable]. Moscow: Izd-vo Physics and Mathematics Lit, $1958674 \mathrm{p}$.

[9] R. L. Zenkov,; G. P. Grinevich,; V. S.Isaev, Bunkernye ustrojstva [Bunker devices].Moscow: Mashinostroenie, 1966, 234 p. Available: http://science.totalarch.com/book/3939.rar. Access: 25th November, 2018.

[10] S. Sous, Gidrodinamika mnogofaznyx sistem [Hydrodynamics of multiphase systems]. Moscow: Mir, 1971, 536 p.

[11] K. Dziedzic, B. Łapczyńska-Kordon, K. Mudryk, M. Wróbel Decision support systems to establish plantations of energy crops on the example of willow (Salix Viminalis L.). Scientific achievements in agricultural engineering, agronomy and veterinary medicine polish ukrainian cooperation. Vol. 1, No. 1, 2017, p.150-160. Available: http://188.190.33.56:7980/jspui/ bitstream/123456789/858/1/SCIENTIFIC\%20ACHIEVEMENTS.pdf\#page=150. Access: Feb. 09, 2019.

[12] S.Yermakov, T. Hutsol. Features of the heterogeneous rod-like materials outflow. Technological and methodological aspects of agri-food engineering in young scientist research.Krakow, 2018, pp. 55-68.

[13] R.I. Nyhmatulin, Osnovy mexaniki geterogennyx sred [The basics of mechanics of heterogeneous mediums]. Moscow: Nauka, 1978336 p.

[14] K, Dziedzic, K. Mudryk, T. Hutsol, B. Dziedzic; "Impact of grinding coconut shell and agglomeration pressure on quality parameters of briquette, Engineering for rural development", 2018, pp. 1884-1889. 